\title{
Preparation of Schiff Base Derived from 3,4-Dimethoxybenzaldehyde and $p$-Aminobenzoic Acid by Supersonic Speed Gas Impacting Method
}

\author{
Yan-Hua Cai ${ }^{1}$ and Wen Luo \\ ${ }^{1}$ Chongqing Key Laboratory of Environmental Materials \& Remediation Technologies, \\ Chongqing University of Arts and Sciences, Yongchuan, Chongqing 402160, China \\ ${ }^{2}$ School of Materials Science and Engineering, Chongqing University of Technology, Chongqing 400054, China \\ Correspondence should be addressed to Yan-Hua Cai; caiyh651@aliyun.com
}

Received 28 December 2013; Revised 25 February 2014; Accepted 25 February 2014; Published 15 April 2014

Academic Editor: Ahmet Kilic

Copyright (C) 2014 Y.-H. Cai and W. Luo. This is an open access article distributed under the Creative Commons Attribution License, which permits unrestricted use, distribution, and reproduction in any medium, provided the original work is properly cited.

\begin{abstract}
A Schiff base derived from 3,4-dimethoxybenzaldehyde and p-aminobenzoic acid (SBDA) was synthesized by novel supersonic speed gas impacting method. The morphology and geometric structure of the synthesized Schiff base SBDA were investigated, the results showed that the particles of SBDA were not completely regular and the HOMO and LUMO of SBDA optimized geometry structure using the semiempirical method PM3 were $-9.115 \mathrm{eV}$ and $-1.191 \mathrm{eV}$, respectively, and some bond length of synthesized SBDA became short and bone angle became large compared to the reactant. The thermogravimetric analysis results indicated that SBDA began to decompose above $280^{\circ} \mathrm{C}$; the decomposition temperature and thermogravimetric rate could vary with the different heating rate.
\end{abstract}

\section{Introduction}

Schiff bases, as the most widely used organic compounds, have been widely used in synthesis of intermediates $[1,2]$, biological actions $[3,4]$, polymers $[5,6]$, and so forth and obtained a lot of progress. Schiff bases have been shown to exhibit a broad range of biological activities. Chen et al. [7] reported that a series of $\mathrm{Ru}(\mathrm{III})$ tetrahydro-Schiff base complexes were encapsulated in the supercages of zeolite $\mathrm{Y}$ by flexible ligand method. Upon encapsulation in zeolite $\mathrm{Y}, \mathrm{Ru}(\mathrm{III})$ tetrahydro-Schiff base complexes exhibited higher activity for the hydrogenation of benzene than the corresponding $\mathrm{Ru}(\mathrm{III})$-Schiff base complexes. This indicates that hydrogenation of the $\mathrm{C}=\mathrm{N}$ bond of Schiff base ligands led to a modification of the coordination environment of the central $\mathrm{Ru}(\mathrm{III})$ cations. Nair et al. [8] reported that $\mathrm{Co}(\mathrm{II}), \mathrm{Ni}(\mathrm{II}), \mathrm{Cu}(\mathrm{II})$, and $\mathrm{Zn}(\mathrm{II})$ complexes of the Schiff base derived from indole-3-carboxaldehyde and $m$ aminobenzoic acid were synthesized. The electronic spectral and magnetic moment results indicated that $\mathrm{Co}(\mathrm{II})$ and $\mathrm{Ni}$ (II) complexes had tetrahedral geometry, while $\mathrm{Cu}$ (II) complex was square planar. The results of antimicrobial activity of the synthesized ligand and its complexes show that the metal complexes were found to be more active than the ligand.

Up to now, many methods for the synthesis of Schiff bases had been described; the most widely used method involves the condensation of a carbonyl compound with an amine by liquid reaction, and other innovations and new techniques including grinding, high energy ball mill, and microwave irradiation have been reported with development of science technology in recent years. In our previous work, we had reported a novel solvent-free synthesis method using supersonic speed gas impacting method, and some compounds including Schiff bases were synthesized by this method [9-12]. To synthesize more compounds and confirm the advantage of this technology, in this paper, we synthesized 


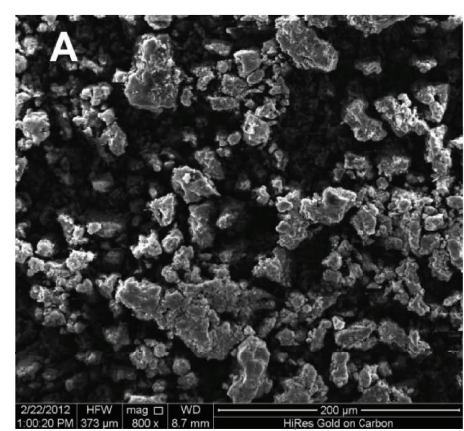

(a)

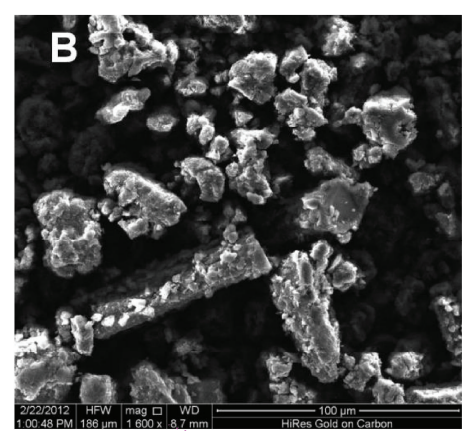

(b)

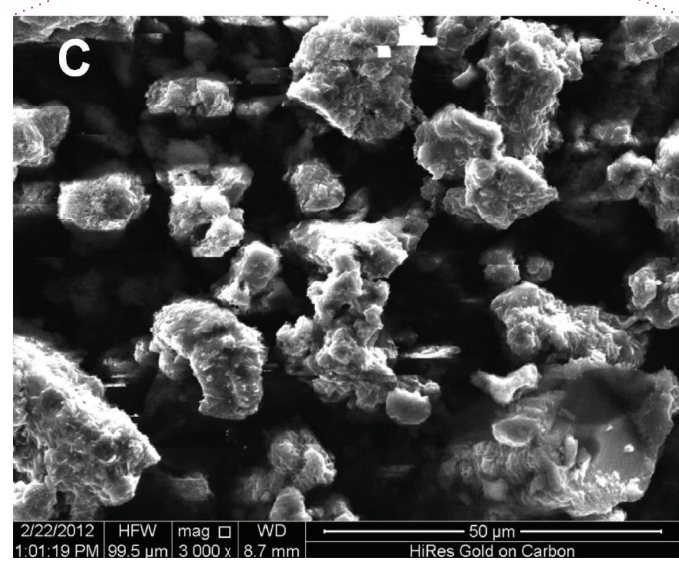

(c)

FIGURE 1: SEM of SBDA.

Schiff base derived from 3,4-dimethoxybenzaldehyde and $p$ aminobenzoic acid (SBDA) by supersonic speed gas impacting method, and the morphology, geometric structure, and thermal stability of synthesized SBDA were investigated.

\section{Experimental Section}

2.1. Materials. 3,4-Dimethoxybenzaldehyde and p-aminobenzoic acid in this study were of analytical grade (AR).

2.2. Synthesis of SBDA. The type synthesis process of Schiff base has been described in our previous paper [9-12], and the SBDA was synthesized as shown in Scheme 1. 3,4Dimethoxybenzaldehyde and $p$-aminobenzoic acid, in a $1: 1$ molar ratio, were mixed; then the mixture was accelerated to supersonic and reacted at a fixed target. The product was collected after quantitative reaction and dried in a vacuum at $60^{\circ} \mathrm{C}$. IR $\left(\mathrm{KBr}, \mathrm{V}_{\max }, \mathrm{cm}^{-1}\right): 3455.1(\mathrm{O}-\mathrm{H}), 2836.2(\mathrm{C}-\mathrm{H})$, $1674.4(\mathrm{C}=\mathrm{O}), 1625.9(\mathrm{~N}=\mathrm{C}), 1577.3,1510.1,1452.7$ (Ar), 1168.4 (C-O), 809.5, 771.9 (Ar-H); ${ }^{1} \mathrm{H}$ NMR (d6-DMSO, $500 \mathrm{MHz}$, ppm) $\delta: 12.06(\mathrm{~s}, 1 \mathrm{H}, \mathrm{Ar}-\mathrm{COOH}), 8.54(\mathrm{~s}, 1 \mathrm{H}, \mathrm{CH}=\mathrm{N}), 6.58 \sim$ $7.63(\mathrm{~m}, 7 \mathrm{H}, \mathrm{Ar}), 3.86\left(\mathrm{~s}, 6 \mathrm{H}, \mathrm{Ar}-\mathrm{OCH}_{3}\right)$.

2.3. Characterization. Fourier transform infrared spectra (FT-IR) were recorded on a Bio-Rad FTS135 spectrophotometer from 4000 to $400 \mathrm{~cm}^{-1}$. The sample of SBDA was mixed with $\mathrm{KBr}$ powders and pressed into a disk suitable for IR measurement.
The ${ }^{1} \mathrm{H}$ nuclear magnetic resonance $\left({ }^{1} \mathrm{H}\right.$ NMR) of SBDA was recorded on Brucker AVANCE 300 spectrometers. The solvent was dimethyl sulphoxide (DMSO).

The morphologies of SBDA were examined by XL-30 ESEM FEG, Philips, in $15-20 \mathrm{kV}$ accelerating voltage (tungsten filament).

Thermogravimetric analysis (TGA) was performed using a simultaneous thermal analysis Q500 (TA instrument USA) with a heating ramp of 5,10 , and $20^{\circ} \mathrm{C} / \mathrm{min}$ under nitrogen flow $(50 \mathrm{~mL} / \mathrm{min})$ from room temperature to $600^{\circ} \mathrm{C}$.

\section{Results and Discussion}

3.1. Morphology and Geometric Structure of SBDA. Morphology of synthesized SBDA was observed by SEM (B and C are the partly amplificatory images of $A$, resp.). As seen in Figure 1, the particles of SBDA are not completely regular. However, most of the particles are column or lump, and the thickness of lump particles is about $10 \mu \mathrm{m}$. It is a fact that there exist large and small particles, resulting from uneven mixing during reaction and purification or van der Waals and Coulombic forces between the particles. The results of SEM also indicate that it is difficult to control the morphology of synthesized compound by supersonic speed gas impacting method.

The optimized geometric structure of SBDA was carried out by the theoretical calculation, and the calculations were performed with the program VAMP using 

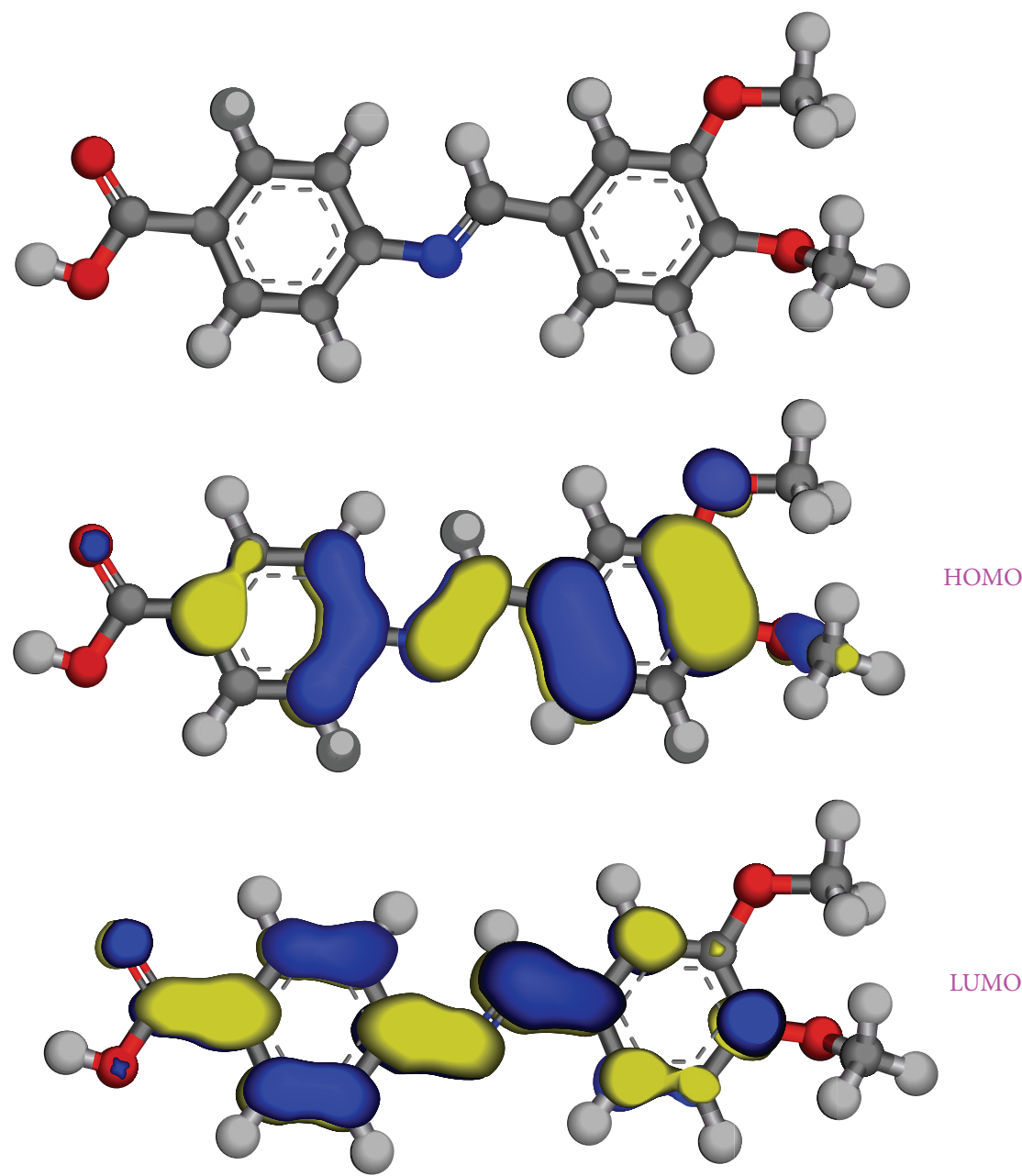

FIgure 2: Optimized geometric structure, HOMO, and LUMO of SBDA.<smiles></smiles>

Scheme 1: Synthesis of SBDA.

the semiempirical method PM3 as our previous work [13]. The optimized geometry structure of SBDA is shown in Figure 2, and the HOMO and LUMO of SBDA are $-9.115 \mathrm{eV}$ and $-1.191 \mathrm{eV}$, respectively. As shown in Figure 2, the active electronics of HOMO focus on side of $\mathrm{C}=\mathrm{N}$, especially the benzene of 3,4-dimethoxybenzaldehyde. However, the electronics receptor of LUMO disperses in the whole compound compared to the active electronics of HOMO.

Some bond lengths and bond angles of optimized SBDA were listed in Table 1. Compared to the bond length of C3-C5 of 3,4-dimethoxybenzaldehyde, the bond length of C3-C5 of the synthesized SBDA decreases from $1.485 \mathrm{~nm}$ to $1.466 \mathrm{~nm}$, and the bond angle of $\angle \mathrm{H} 4 \mathrm{C} 3 \mathrm{C} 5$ of the synthesized SBDA is larger than that of 3,4-dimethoxybenzaldehyde. These
TABLE 1: Some bond lengths and bond angles of SBDA.

\begin{tabular}{lclc}
\hline & Bond length/Å & & ${\text { Bond angle } /^{\circ}}$ \\
\hline C1-N2 & 1.432 & $\angle \mathrm{C} 1 \mathrm{~N} 2 \mathrm{C} 3$ & 121.844 \\
$\mathrm{~N} 2-\mathrm{C} 3$ & 1.297 & $\angle \mathrm{N} 2 \mathrm{C} 3 \mathrm{H} 4$ & 121.441 \\
$\mathrm{C} 3-\mathrm{H} 4$ & 1.109 & $\angle \mathrm{H} 4 \mathrm{C} 3 \mathrm{C} 5$ & 117.352 \\
$\mathrm{C} 3-\mathrm{C} 5$ & 1.466 & & \\
\hline
\end{tabular}

results indicate that $p$-aminobenzoic acid makes C3-C5 of 3,4-dimethoxybenzaldehyde extruded and the geometry structure becomes wide. Meantime, the bond length of $\mathrm{Cl}-$ $\mathrm{N} 2$ of the synthesized Schiff base decreases from $1.423 \mathrm{~nm}$ to $1.432 \mathrm{~nm}$ compared to that of $p$-aminobenzoic acid. 


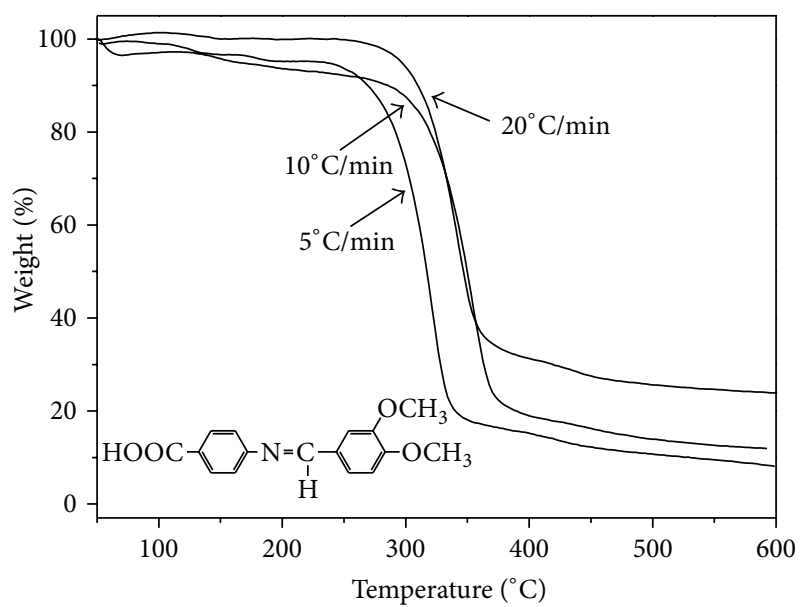

FIGURE 3: TGA of SBDA with different heating rate.

3.2. Thermal Properties of SBDA. Usually, thermal properties of materials can obviously affect the application; thus, it is necessary to investigate the thermal properties of compound. Figure 3 shows the thermal stability of SBDA with a heating ramp of 5,10 , and $20^{\circ} \mathrm{C} / \mathrm{min}$ under nitrogen flow from room temperature to $600^{\circ} \mathrm{C}$. As seen in Figure 3, SBDA begins to decompose above $280^{\circ} \mathrm{C}$, which suggests that SBDA has good thermal stability under mild conditions, and it is clear that the decomposition temperature increases with the increasing of heating rate; similar results can be found in decomposition process of other compounds $[9,10,14,15]$. The reason of this phenomenon is that decomposition of SBDA is not achieved at set temperature because of rapid heating rate. Meanwhile, the program temperature has got into the following set temperature, resulting in decomposition achieving at higher temperature. The results of decomposition process significantly indicated that the decomposition temperature and thermogravimetric rate of SBDA are affected by heating rate.

\section{Conclusion}

In this paper, a Schiff base derived from 3,4-dimethoxybenzaldehyde and $p$-aminobenzoic acid was successfully synthesized by novel supersonic speed gas impacting method. We investigated the morphology, geometric structure, and thermal stability of synthesized Schiff base, SEM showed the particles of SBDA were not completely regular, and the HOMO and LUMO of SBDA were $-9.115 \mathrm{eV}$ and $-1.191 \mathrm{eV}$, respectively. TGA result indicated good thermal stability of SBDA under mild conditions.

\section{Conflict of Interests}

The authors declare that there is no conflict of interests regarding the publication of this paper.

\section{Acknowledgments}

This work was supported by China Postdoctoral Science Foundation (Project no. 2013M531937), Natural Science Foundation Project of CQ CSTC (Project no. cstc2012jjA50001), Postdoctoral Science Foundation Project of Chon-gqing (Project no. XM20120035), Scientific and Technological Research Program of Chongqing Municipal Education Commission (Project no. KJ131202), and Chongqing University of Arts and Sciences (Project nos. R2012CH10, 2012PYXM04, and Z2011CL11).

\section{References}

[1] H.-P. Jia, W. Li, Z.-F. Ju, and J. Zhang, "Synthesis, crystal structure and magnetic properties of an oxalate-bridged diiron(III) complex [FeIII(salapn) $]_{2}\left(\mathrm{C}_{2} \mathrm{O}_{4}\right)$," Journal of Molecular Structure, vol. 833, no. 1-3, pp. 49-52, 2007.

[2] A. Pui, C. Policar, and J.-P. Mahy, "Electronic and steric effects in cobalt Schiff bases complexes: synthesis, characterization and catalytic activity of some cobalt(II) tetra-halogens-dimethyl salen complexes," Inorganica Chimica Acta, vol. 360, no. 6, pp. 2139-2144, 2007.

[3] T. B. S. A. Ravoof, K. A. Crouse, M. I. M. Tahir, A. R. Cowley, and M. A. Ali, "Synthesis, characterization and bioactivity of mixed-ligand $\mathrm{Cu}(\mathrm{II})$ complexes containing Schiff bases derived from S-benzyldithiocarbazate and saccharinate ligand and the X-ray crystal structure of the coppersaccharinate complex containing S-benzyl- $\beta$-N-(acetylpyrid-2yl)methylenedithiocarbazate," Polyhedron, vol. 26, no. 6, pp. 1159-1165, 2007.

[4] D.-H. Shi, Z.-L. You, C. Xu, Q. Zhang, and H.-L. Zhu, "Synthesis, crystal structure and urease inhibitory activities of Schiff base metal complexes," Inorganic Chemistry Communications, vol. 10, no. 4, pp. 404-406, 2007.

[5] S. M. El-Saeed, R. K. Farag, M. E. Abdul-Raouf, and A.-A. A. Abdel-Azim, "Synthesis and characterization of novel crude oil dispersants based on ethoxylated Schiff base," International Journal of Polymeric Materials, vol. 57, no. 9, pp. 860-877, 2008.

[6] N. Nishat, S. Parveen, S. Dhyani, A. Asma, and T. Ahamad, "Synthesis, characterization, and thermal and antimicrobial studies of newly developed transition metal-polychelates derived from polymeric Schiff base," Journal of Applied Polymer Science, vol. 113, no. 3, pp. 1671-1679, 2009.

[7] P. Chen, B. Fan, M. Song, C. Jin, J. Ma, and R. Li, "Zeoliteencapsulated $\mathrm{Ru}(\mathrm{III})$ tetrahydro-Schiff base complex: an efficient heterogeneous catalyst for the hydrogenation of benzene under mild conditions," Catalysis Communications, vol. 7, no. 12, pp. 969-973, 2006.

[8] M. S. Nair, D. Arish, and R. S. Joseyphus, "Synthesis, characterization, antifungal, antibacterial and DNA cleavage studies of some heterocyclic Schiff base metal complexes," Journal of Saudi Chemical Society, vol. 16, no. 1, pp. 83-88, 2012.

[9] Y. H. Cai, "Synthesis and properties of Schiff bases with nitro by Gas flow crushing," Asian Journal of Chemistry, vol. 24, no. 10, pp. 4468-4470, 2012.

[10] S.-J. Li and Y.-H. Cai, "Synthesis, morphology and thermal decomposition of schiff base derived from $m$ hydroxybenzaldehyde and p-aminobenzoic acid," Asian Journal of Chemistry, vol. 23, no. 6, pp. 2619-2621, 2011.

[11] Y.-H. Cai, R.-F. Peng, S.-J. Chu, and J.-B. Yin, "Synthesis of schiff base derived from $p$-aminobenzoic acid by solvent-free reaction 
using jet milling," Asian Journal of Chemistry, vol. 22, no. 8, pp. 5835-5840, 2010.

[12] Y. H. Cai, R. Peng, and S. Chu, "Preparation of ultra-fine calcium carbonate by a solvent-free reaction using supersonic airflow and low temperatures," South African Journal of Chemistry, vol. 61, pp. 112-114, 2008.

[13] Y. H. Cai, "Solvent-free synthesis of phthalimide under microwave irradiation and modification of Talc with synthesized phthalimide," Asian Journal of Chemistry, vol. 24, no. 2, pp. 481-484, 2012.

[14] Y.-H. Cai, "Synthesis, process, morphology and thermal stability of $N, N^{\prime}$-Bis(benzoyl) tridecanedioic acid dihydrazide," Asian Journal of Chemistry, vol. 23, no. 6, pp. 2622-2624, 2011.

[15] Y. H. Cai, "Synthesis and properties of Schiff bases with nitro by Gas flow crushing," Asian Journal of Chemistry, vol. 24, no. 10, pp. 4468-4470, 2012. 

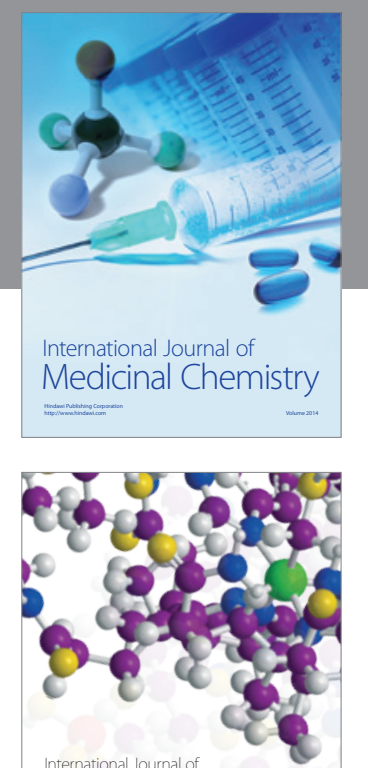

\section{Carbohydrate} Chemistry

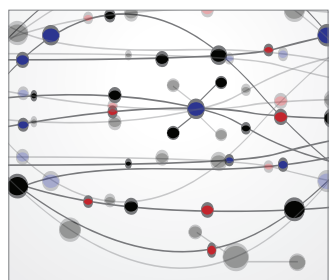

The Scientific World Journal
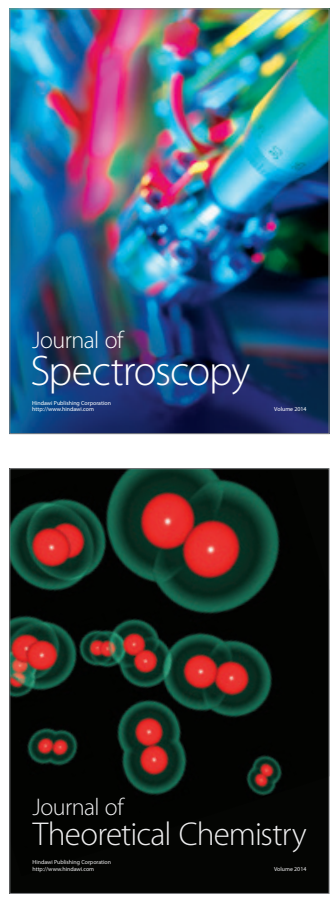
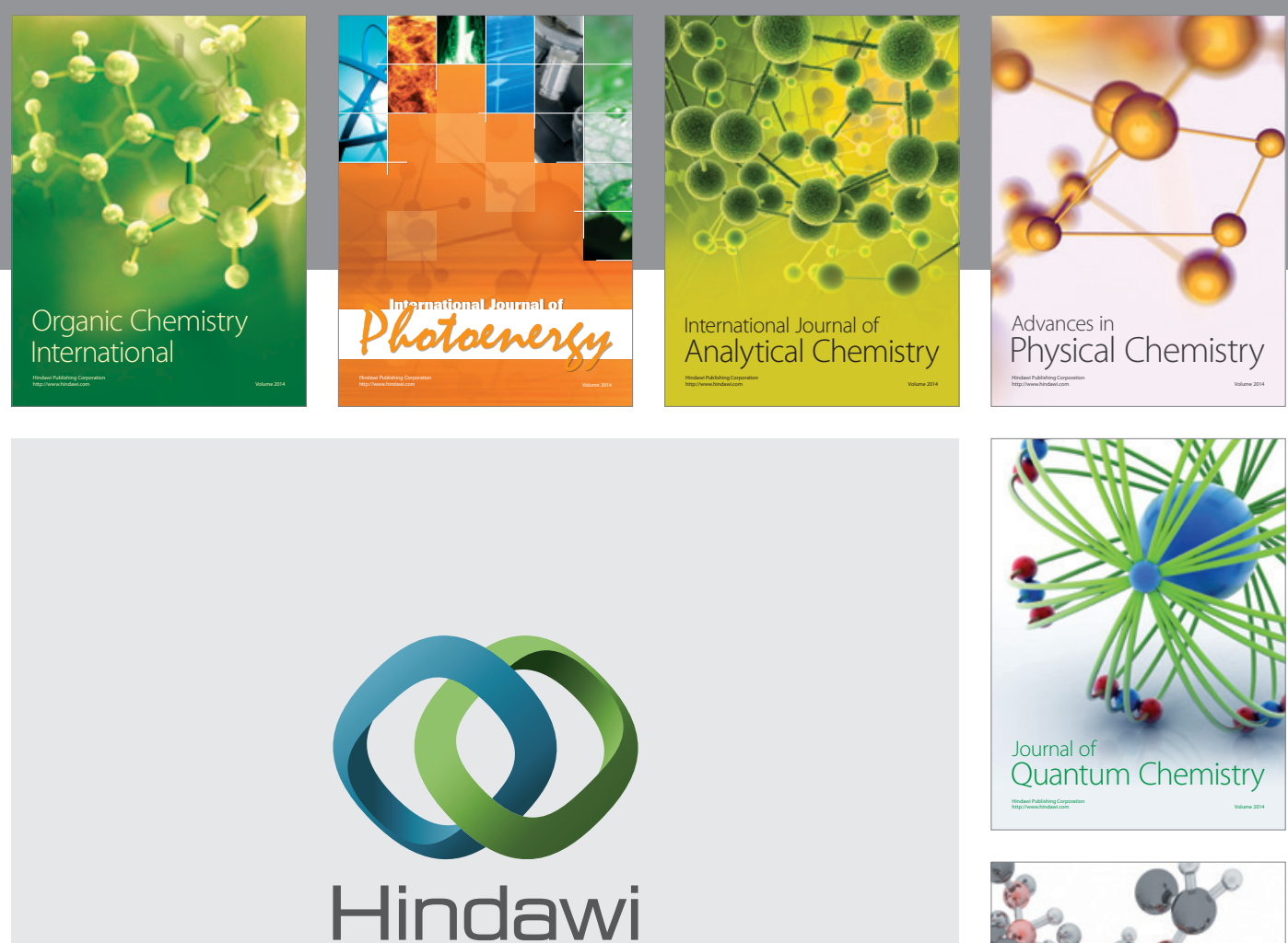

Submit your manuscripts at

http://www.hindawi.com

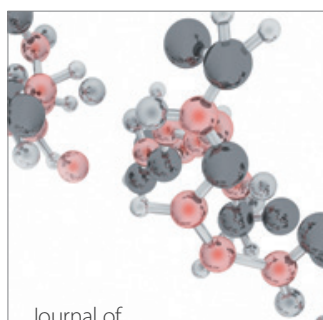

Analytical Methods

in Chemistry

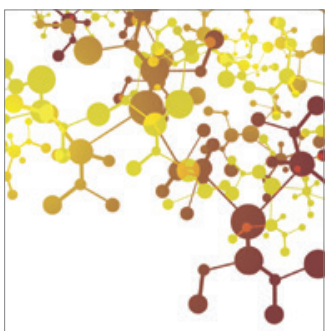

Journal of

Applied Chemistry

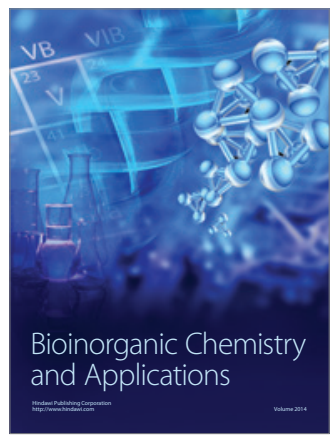

Inorganic Chemistry
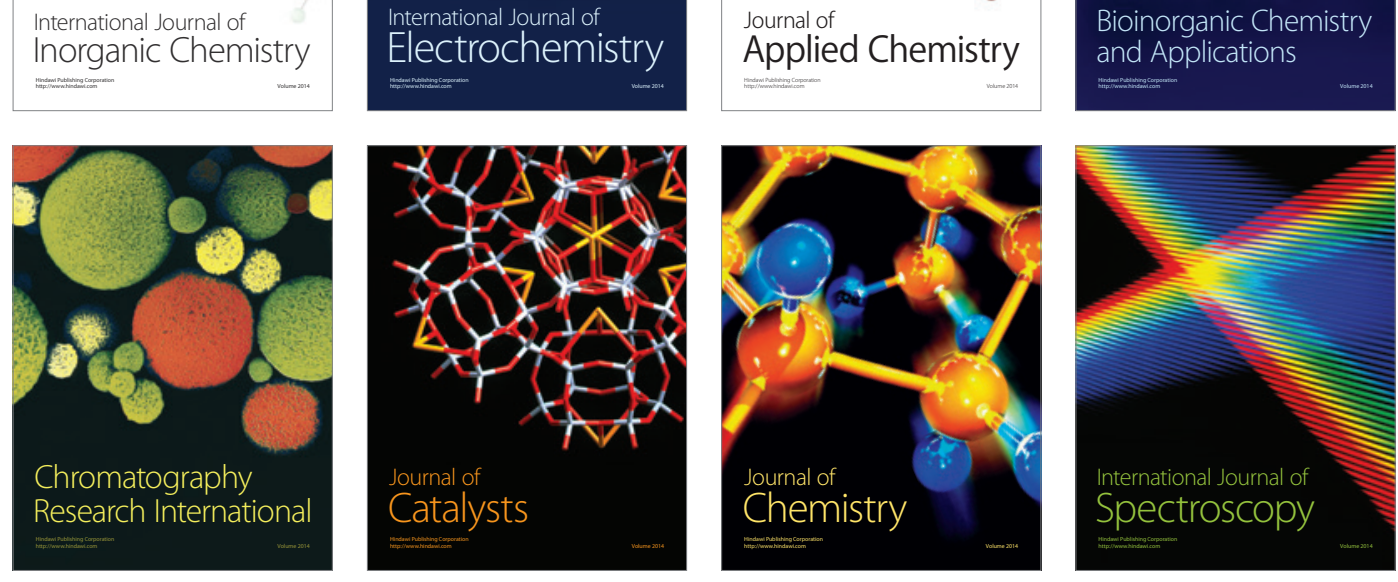